\title{
"Murió don Heriberto y los tambores y los cantos cesaron". Una aproximación a la tambora en el contexto de las políticas culturales de la Revolución en Marcha en Colombia, 1930-1946
}

Resumen: El presente artículo indaga por las vivencias de un cantador de tambora y por una comunidad cuya visibilidad nacional fue determinada por sus prácticas musicales orales. A través de la revisión de acontecimientos microhistóricomusicales ocurridos en la Ciénaga de Zapatosa, paralelos a la difusión de las políticas culturales de la Revolución en Marcha de 1930-1946 en Colombia, se evidencia cómo este proyecto nacional, impulsado por los intelectuales liberales, tuvo efectos regresivos para dichas prácticas musicales.

Palabras clave: cantador, Revolución en Marcha, cancionero aldeano, microhistoria.

\section{"Don Heriberto died and the tambores and singings ceased." An approach to the tambora in the context of the cultural policies of the Revolución en Marcha in Colombia, 1930-1946}

Abstract: This article explores the life experiences of a tambora folksinger and casts light on a community whose visibility on the national stage was shaped by its musical practices. By adopting a microhistorical approach to the study of musical events that took place in the Ciénaga de Zapatosa and of the dissemination of cultural policies implemented in La Revolución en Marcha from 1930 to 1946 in Colombia, the article shows how this national project, promoted by intellectual liberals, had regressive effects on the musical practices themselves.

Keywords: folksinger, Revolución en Marcha, villager songbook, microhistory.

\section{“Don Heriberto morreu e os tambores e canções cessaram”. Uma abordagem ao tambora no contexto das políticas culturais da Revolución en Marcha na Colômbia, 1930-1946}

Resumo: Este artigo explora as experiências de um cantor de tambora e de uma comunidade cuja visibilidade nacional foi determinada por suas práticas musicais orais. Através da revisão dos eventos microhistóricos musicais que ocorreram na Cienaga de Zapatosa em paralelo com a difusão das políticas culturais da Revolución en Marcha de 1930 - 1946 na Colômbia, será evidente como esse projeto nacional, promovido pelos intelectuais liberais, tiveram efeitos regressivos para as ditas práticas musicais.

Palavras-chave: cantor, Revolución en Marcha, songbook do aldeão, micro-história.

Cómo citar este artículo: Bernardo A. Ciro Gómez, "'Murió don Heriberto y los tambores y los cantos cesaron'. Una aproximación a la tambora en el contexto de las políticas culturales de la Revolución en Marcha en Colombia, 19301946”, Trashumante. Revista Americana de Historia Social 14 [2019]: 150-173.

DOI: 10.17533/udea.trahs.n14a07

Fecha de recepción: 1 de junio de 2018

Fecha de aprobación: 5 de noviembre de 2018

Bernardo A. Ciro Gómez: Magíster en Artes de la Universidad de Antioquia. Docente investigador de la

Escuela Superior Tecnológica de Artes Débora Arango.

Correo electrónico: bciro@deboraarango.edu.co 


\title{
"Murió don Heriberto y los tambores y los cantos cesaron". Una aproximación a la tambora en el contexto de las políticas culturales de la Revolución en Marcha en Colombia, 1930-1946
}

Bernardo A. Ciro Gómez

\section{Introducción}

\begin{abstract}
Dara comenzar, es importante mencionar que la presente investigación se llevó a cabo con la comunidad musical del municipio de Chimichagua en el departamento del Cesar en el año 2017. Este es uno de los productos asociados a las búsquedas musicales que adquirió una intencionalidad especial, debido a que se aproximó a algunas lecturas y reflexiones a partir de la conferencia "Historia, memoria y fuentes" impartida por Giovanni Levi. Sobre todo fue muy estimulante en la conferencia la respuesta que se dio a la pregunta de cómo vincular la microhistoria en la investigación de campo de las músicas colombianas de tradición oral. Así fue la respuesta del profesor Levi:
\end{abstract}

\footnotetext{
Esto es un tema importante en microhistoria [... él [se refiere a Mauricio, un colega suyo] estudiaba música popular $[\ldots]$ estudió un hecho muy importante y muy poco estudiado, [...] investigó cómo en los registros de música popular se utilizaba las notas y descubrió que, entre las notas do y re por ejemplo, había otras notas, e hizo una reconstrucción general de esta especificidad de la música popular, que antes ninguno había considerado, todos hacían las transcripciones con las notas normales... si se puede decir. Ahora, esto es un ejemplo de intensa lectura microhistórica de una característica musical de la música popular. Deberías de pensar qué pasa con relación a estas cosas. Para registrar canciones populares, efectivamente se necesita de buen oído, pero él quería algo extra-musical. ${ }^{1}$
}

El concepto extra-musical utilizado por Levi llama la atención en tanto que orienta hacia otras posibilidades de indagación del fenómeno musical. Potencialidades para la investigación que bien podrían girar en coordenadas dirigidas desde una exploración de las discrepancias texturales mencionadas y su relación con la

1. Giovanni Levi, "Historia, memoria y fuentes" (Conferencia, Universidad de Antioquia, 2016). 
realidad social de los grupos humanos, ${ }^{2}$ hasta su proyección en los acontecimientos históricos que han marcado sus formas de resistencia, como es el caso de las prácticas de tradición oral ante las narrativas de la historia oficial. Este último aspecto debe ser considerado como un campo extenso y escasamente explorado por los desarrollos de la historia de la música en Colombia, lo que dificulta el conocimiento y reconocimiento de otras comprensiones de arte y de música en sus entramados sociales como la tambora chimichagüera, además de sus procesos de transformación según las dinámicas propias del territorio. Se analizarán los testimonios orales de algunos referentes que compartieron o documentaron las correrías del cantador Heriberto Pretel y los archivos documentales del entonces ministro de Educación de Colombia, ${ }^{3}$ junto con textos significativos como Historia de la música en Colombia y los análisis sobre la Encuesta Folclórica Nacional de 1942, entre otros.

De esta forma, se pretenderá aproximar algunas reflexiones extra-musicales que permitan reconstruir las historias alrededor de la vida de Heriberto Pretel y de la tambora chimichagüera. ${ }^{4}$ Asimismo, se indagará sobre cómo un acontecimiento paralelo como lo fue la difusión de las políticas culturales impulsadas por los intelectuales liberales de la Revolución en Marcha de 1930-1946, quienes tenían la visión de expandir la "cultura" a los territorios alejados de la urbe, provocó efectos regresivos que se manifiestan actualmente en el poco reconocimiento a las prácticas musicales de tradición oral en Colombia.

\section{Heriberto Pretel y la tambora chimichagüera}

"Chimichagua ha poseído rasgos culturales — costumbres, expresiones, prácticasque lo distingue de otros municipios costeños. Por ejemplo [...] El peculiar toque y canto de la tambora". Esto escribiría Ismael Medina Lima en el año de 1990. Su interés por reconstruir la historia del municipio lo llevó a ser el único en entrevistar en 1988 a Heriberto Pretel Méndez, pocos días antes de su muerte. ${ }^{6}$ En la entrevista hecha por Medina Lima, Pretel contó que cuando era niño, su padre, un músico de la banda del municipio, fue asesinado tratando de huir de la Guerra

2. Charles Keil define como discrepancias texturales o tímbricas a la existencia de afinaciones diferentes a la impuesta por la música occidental. Charles Keil, "Las discrepancias participatorias y el poder de la música”, Las culturas musicales. Lecturas de etnomusicología, eds. Francisco Cruces y otros (Madrid:Trotta, 2008) 261.

3. Los testimonios orales se refieren a bailes y parrandas comunitarias.

4. La tambora es una manifestación de tradición oral que se divulga en la Depresión Momposina colombiana y consta de un cantador o cantadora, dos tamboreros, maracas, bailadores y un coro responsorial. El texto abordará la tambora de Chimichagua, Cesar.

5. Ismael Medina, Chimichagua en la memoria de los abuelos (Cali:Arte Libro Impresores, 2005) 13.

6. El cantador murió el día 14 de julio de 1988 de un paro cardiorrespiratorio, tenía 88 años. "Diócesis de El Banco. Libro 3 de Defunciones de la parroquia La Inmaculada Concepción de Chimichagua", Chimichagua, Cesar, 14 de julio de 1988, Parroquia de La Inmaculada Concepción de Chimichahua, Colombia, n. 32, f. 220. 
de los Mil Días y su madre murió cuando él tenía diecinueve años, por lo cual el cantador se desplazó hacia un corregimiento de Chimichagua, llamado Plata Perdida, ubicado a 20 minutos de la cabecera municipal. ${ }^{7}$ Heriberto construyó allí un pequeño rancho donde pasó la mayor parte del tiempo oculto por el temor que desató en toda esta subregión la guerra entre liberales y conservadores. ${ }^{8}$

Desde el año 1910, con tan solo diez años de edad Heriberto Pretel, además de dedicarse a la agricultura, ya se destacaba por cantar tamboras; con el paso de los años adquirió un significativo reconocimiento como compositor y parrandero en las fiestas. ${ }^{9}$ Asimismo, un interlocutor de Medina Lima le hizo saber lo importante que era la tambora en 1914 y, aunque no mencionó el nombre de Heriberto Pretel, se infiere que estuvo ahí cantando tamboras. "La mejor fiesta aquí era San Pedro [...] mejor que la del 8 de diciembre [...] había tamboras, salían diablos, cucambas, negros, no, no [...] la víspera en la noche no dormía la gente con el golpe de tambores [...] venía gente de todas partes". ${ }^{10}$ Hacia 1919, Pretel, consumado cantador, asociaba sus labores del campo con el canto de la tambora. Al igual que la mayoría de niños y jóvenes, renunció a sus estudios en la escuela, pues por este tiempo atravesaba una fuerte crisis económica. ${ }^{11}$ Se vio obligado a engancharse en el precario mercado laboral que brindaban las bonanzas azucarera y panelera del municipio, ya que el principal producto de Chimichagua en esta época era la panela, que vendían como melao ${ }^{12}$ a la alcoholina del Banco para preparar el Ron Viejo de la Costa. ${ }^{13}$

7. Medina, Chimichagua 59; Ismael Medina, Mi Chimichagua de ayer (Cali: Arte Libro Impresores, 1990) 73-74.

8. La historiadora Carmen Queruz dice que en el municipio, donde las mayorías eran conservadoras y unos pocos liberales, después de escuchar por la radio sobre el asesinato de Gaitán esperaron la orden para iniciar la guerra. No obstante, el jefe del partido liberal, se dirigió al pueblo diciendo "todos somos familia [...] Vamos a dejar nuestras mujeres viudas y a sus niños huérfanos [...] eso es una pelea entre cachacos, que se maten ellos allá". Entrevista de Bernardo A. Ciro a Carmen Ligia Queruz, Chimichagua, Cesar, 17 de noviembre de 2017. Sin embargo, los campesinos que contaban también con radio escucharon vociferar a los locutores: "A las armas, a la carga, a la calle, con palos, piedras y escopetas, cuanto haya a la mano [...]"; véase Indalecio Castellanos, "Así registró la radio de la época la muerte de Jorge Eliecer Gaitán”, NoticiasRCN.com (Bogotá) 9 de abril del 2018. www.noticiasrcn.com/nacional-pais/asi-registro-radio-epoca-muertejorge-eliecer-gaitan (21/04/2018). Esta situación hizo que muchos campesinos atemorizados se alejaran de Chimichagua y se ocultaran en el campo, entre ellos don Heriberto. Entrevista de Bernardo A. Ciro Gómez a Héctor Rapalino, Chimichagua, Cesar, 17 de noviembre de 2017.

9. Medina, Mi Chimichagua 71-74.

10. Medina, Mi Chimichagua 24.

11. Entre los años 1921 y 1922 Colombia vivió una crisis fiscal que afectó principalmente el apoyo a las escuelas. Esta crisis provocó altos índices de deserción escolar en el Magdalena (todavía no existía el departamento del Cesar).Véase Ministerio de Instrucción Pública, Memoria del ministro de Instrucción Pública al Congreso de 1923 (Bogotá: Casa Editorial de la Cruzada, 1923) 30, 153.

12. Producto parecido al caramelo que se obtiene cuando se licúa panela en una pequeña cantidad de agua.

13. Medina, Chimichagua 16. 
Pretel participó activamente cantando tamboras en estas festividades cuando era ya un compositor reconocido por la comunidad. Además, componía tamboras muy recordadas por los chimichagüeros tales como "Candela viva", canción que, según los investigadores de Chimichagua y los hijos de Heriberto, se apropió Totó la Momposina para su álbum "La candela viva" que se lanzó en el año de 1993. ${ }^{14}$ Esta composición nació a raíz del gran incendio en Chimichagua en 1923, tal como lo relató el propio Pretel en 1988:

-Ismael Medina: ¿Fue cierto que usted compuso otra tambora que se llama "Candela Viva"?

- Heriberto Pretel: Sí, también [...] Eso fue cuando se quemó Chimichagua, fue en el incendio $[\ldots]$ Yo ejtaba $[\ldots]$ durmiendo en $[\ldots]$ una mesa allá ande el hermano mío, cuando ví la cuejtión de loj tiro [...] me levanté y me di una vuelta por el monte [...] No había gente en el pueblo porque ejtaba prendío y la gente ejtaba en loj campo [...], en el cementerio, metíoj po allá llorando. ${ }^{15}$

De igual forma, Hernán Martínez, reconocido gestor cultural del municipio de Chimichagua, afirmó:

la candela viva [...] que canta: fuego, fuego, fuego, eso es de aquí también, dice que se quema ya Talaigua, ¡bueno! son adaptaciones que le puso Totó, pero los versos no coinciden, [...] hasta la misma Totó la momposina cuando [la] interpretó [...] dice [entra la tambora, el tamborero ejecuta un ritmo diferente a la tambora chimichagüera y Totó le llama la atención] ¡no señor!, y qué fue lo que pasó, que ella trataba de ubicarse en los versos [...] y tocarla similar acá a Chimichagua $[\ldots]$ luego [el tamborero] cambia y le pone el ritmo de la tambora chimichagüera y ella dice ¡ese sí es, ese sí es! ${ }^{16}$

Tanto Ismael Medina como Hernán Martínez y otros referentes musicales e investigadores comparten estas apreciaciones de "peculiar toque y canto de la tambora", en el caso del primero, y "tocarla similar acá a Chimichagua”, en el caso del segundo. Subrayan con ello dos aspectos importantes desde sus conocimientos extra-musicales. El primero tiene que ver con la importancia de la tambora como hecho social y cómo a través de ella Heriberto Pretel narró acontecimientos históricos relevantes que marcaron la vida de la comunidad. Por su parte, el segundo aspecto está referido a cómo su percepción como oyentes de los acentos musicales de la tambora chimichagüera ha sido un factor principal al cual se han adscrito, y desde el cual demarcan determinados límites que les permiten identificar lo que consideran como propio y las formas de ejecución de otros circuitos de transmisión.

14. Totó la Momposina, "La candela viva", Totó la Momposina y sus tambores (Reino Unido: Real Worl Record, 1993). https://www.discogs.com/es/Tot\%C3\%B3-La-Momposina-Y-Sus-Tambores-La-Candela-Viva/release/631839 (15/11/2017).

15. Medina, Mi Chimichagua 97.

16. Entrevista de Bernardo A. Ciro Gómez a Hernán Martínez, Chimichagua, Cesar, 27 de noviembre de 2017. 


\section{Rutas musicales por la ciénaga de Zapatosa}

De otro lado, a partir del mismo año en que ocurrió el incendio en Chimichagua, la actualmente llamada ciénaga de Zapatosa, conformada por los municipios de Chiriguaná, Curumaní, El Banco, Tamalameque, El Paso, y principalmente por las Playas de Amor de Chimichagua, fue una importante vía fluvial. Así se pudo comprobar en la entrevista de Medina Lima a Antonio Laitano, "el señor de las lanchas" en 1983; quien le narró lo siguiente: "se viajaba por el río Cesar a Chiriguaná, El Banco y El Paso. Venía la gente de Valledupar a embarcarse en Chiriguaná para el Banco y de allí a Bogotá o donde fuera, porque no había más vía, no había carretera". ${ }^{17}$

Se considera importante resaltar esta vía fluvial, debido a que se dieron acontecimientos notables como la presencia en la subregión del músico Lucho Bermúdez, en 1931, y los constantes recorridos realizados por el compositor José Benito Barros en 1927. ${ }^{18}$ No obstante, hubo un hecho que para la presente investigación se considera significativo en estas rutas musicales y que al parecer solo comentan aquellos que conocieron la historia de Heriberto Pretel. Este hecho tiene que ver con sus correrías con el cantautor de música vallenata de El Paso, Cesar,Alejandro Durán, aproximadamente en el año de 1942, según indican los interlocutores, y ocurrió en el momento en que decayó la producción de la caña de azúcar y de la panela, lo cual dio un giro en el uso del suelo hacia la ganadería extensiva. ${ }^{19}$ Así lo narró Dolores "Lole" Pretel: "Yo empecé a trabajar en las fincas de caña a la edad de siete años [1942] [...] yo sé por qué se acabaron, porque la panela se achichaba, la llevaban para Chiriguaná [pero] no había quien le comprara la panela del finado Castrillo, y en El Banco eso que ni se diga, por eso acabaron las fincas de caña [...] y empezaron a poner pasto para meter ganado". ${ }^{20}$

Con relación al cambio en el uso del suelo de Chimichagua coinciden "Chichi” Rapalino y Hernán Martínez en que este cambio trajo a los vaqueros de El Paso, entre quienes se encontraba Alejandro Durán. Durán conoció a Heriberto Pretel, quien ya tenía 42 años, en un momento histórico-musical en el cual los

17. Medina, Chimichagua 15.

18. Sergio Santana, Lucho Bermúdez. Cumbias, porros y viajes (Medellín: Ediciones Santo Bassilón, 2012) 30-35; Entrevista de Bernardo Hoyos a José Barros, Bogotá, 1984. www.utadeo.edu.co/es/multimedia/emisora-hjut/40076/jose-barros-1915-2007 (30/10/2017).

19. En el municipio de Chimichagua se ocuparon grandes extensiones de territorio para potreros, pastoreo y alimentación de la ganadería; véase Luis Flores y otros, Atlas lingüístico-etnográfico de Colombia. Ganadería, animales domésticos y animales silvestres, t. 2 (Bogotá: Instituto Caro y Cuervo, 1982) 2, 3 y 7. Asimismo, Chimichagua ocupó el décimo lugar entre 25 municipios, con el 3,79\% del inventario ganadero del departamento; véase Gobernación del Cesar, "Plan estratégico regional de ciencia, tecnología e innovación. Departamento del Cesar 2007-2011" (Documento oficial, Gobernación del Cesar / Universidad Nacional de Colombia, 2007) 123.

20. Entrevista de Bernardo A. Ciro Gómez a Dolores "Lole" Pretel, Chimichagua, Cesar, 23 de noviembre de 2017. 
cantos de tambora se escuchaban frecuentemente en Chimichagua, mientras que el acordeón, por el contrario, se escuchaba muy ocasionalmente.

Según Hernán Martínez:

en las fiestas de Chimichagua no se escuchaban acordeones, el único acordeón que se escuchaba aquí era esporádicamente cuando llegaba Alejo Durán, amigo de Pretel, pero la tambora sí salía en las fiestas [...] Pero ¡qué ha pasado! tú sabes que anteriormente la ley de los registros [...] no existía prácticamente, entonces aquí cualquiera llegaba y cantaba una tambora de los nativos y la regalaba $[\ldots]$ ni las casas disqueras le pararon bolas a eso, SAYCO [Sociedad de Autores y Compositores de Colombia] aún no existía. Entonces, Heriberto Pretel [...] componía y [...] la mayoría de estas canciones de Heriberto las cogió y las retomó Alejo Durán, como CandelaViva, La Perra, ${ }^{21}$ Mi compadre se cayó, etc. ${ }^{22}$

\section{La tambora chimichagüera y el Cancionero escolar de la Biblioteca Aldeana de Colombia}

Estas correrías de Pretel y de Durán se extenderían por algunos años más; en ellas convocaban a la comunidad a participar de los cantos de tambora y de las melodías del acordeón. Sin embargo, paralelo a estas rutas musicales se habían gestado desde 1934 los proyectos culturales promovidos por la denominada República liberal, entre ellos estaba el primero implementado y conocido como la campaña de Cultura Aldeana y Rural, cuya pretensión más importante, según el historiador Renán Silva, era consolidar una política de Estado orientada hacia la construcción de una cierta representación de la cultura popular. ${ }^{23}$ Si bien la campaña de Cultura Aldeana y Rural surgió como una necesidad de conocer las otras culturas colombianas que habían sido invisibilizadas por considerarse desde el siglo XIX como una manifestación inferior, ${ }^{24}$ de cierta forma violentó el espacio simbólico de las músicas de tradición oral, ${ }^{25}$ pues desconoció la pluralidad de los territorios y cómo

21. Dice Heriberto Pretel a Medina Lima, “'La Perra' [...] esa se la dieron allá a Alejo Durán y él la grabó, pero no así, porque esaj tambora que graba Alejo no son como yo laj saco. Alejo se ha aprovechao. Ej familia mía por lo Pretel [...] él se ha aprovechao bajtante”. Medina, Mi Chimichagua 98-99.

22. Entrevista de Bernardo A. Ciro Gómez a Hernán Martínez, Chimichagua, Cesar, 27 de noviembre de 2017.

23. Renán Silva, "Encuesta Folclórica Nacional, 1942 (Instrucciones para el posible lector)", Historia y Espacio 18 (2002): 7-43.

24. Adolfo González ha analizado la descripción hecha por Carl August Gosselman en su diario de campo entre 1825 y 1826, luego de haber sido invitado a un baile en Cartagena, que posteriormente describiría como "el lenguaje del pueblo inferior". Adolfo González, "La música costeña en la tercera década del siglo XIX”, Boletín Cultural y Bibliográfico 26.19 (1989): 8-9.

25. Egberto Bermúdez hace la siguiente diferenciación: "la música tradicional está constituida por las tradiciones musicales con funciones sociales muy precisas [...] en el marco comunitario de las sociedades rurales [...] la música que se denomina 'popular' se ha consolidado en la cultura urbana $[\ldots]$ abierta al consumo individual $[\ldots]$ y de la llamada industria del entretenimiento $[\ldots]$ ”. 
los cantadores de Chimichagua y de la ciénaga de Zapatosa habían configurado socialmente el canto, el baile y el toque de los tambores. Lo anterior se evidencia al considerar la importancia que tenía el canto como disciplina estética para el entonces ministro de educación, Luis López de Mesa, y la exclusión de los compositores de procedencia rural como Heriberto Pretel. ${ }^{26}$

López de Mesa y otros intelectuales liberales en 1935 intentarían reavivar el ensanchamiento de una cultura artística mediante la imposición del canto en los procesos de enseñanza-aprendizaje con el Cancionero escolar, siguiendo la ruta trazada ya en 1879 por el pedagogo Dámaso Zapata. Al respecto, Ignacio Perdomo en su libro Historia de la música en Colombia reconfirma el liderazgo de Zapata en la introducción de la disciplina estética del canto en la escuela:

El primer esfuerzo en tal sentido en nuestra historia educacional y artística lo encontramos en el llevado a cabo por la ilustre generación de educadores, que brilló de 1870 a 1875 en que se introdujo en la escuela la disciplina estética del canto. La idea surgió de don Dámaso Zapata. ${ }^{27}$ [...] [él] impuso el canto como una característica de la educación pedagógica [...] El hecho fundamental fue haberse sentado las bases para el ensanchamiento de una cultura artística. ${ }^{28}$

No obstante, algunos textos de las piezas musicales del Cancionero escolar parecen seguir la ruta ideológica de lo que el antropólogo Darío Blanco define como "el proyecto de eugenesia cultural colombiano", ${ }^{29}$ si se tiene en cuenta que, como indican Runge y Muñoz: "[López de Mesa] tenía una inclinación hacia asuntos eugenésicos propios de muchas posturas de finales del siglo XIX y comienzos del XX”. Además, dicen los autores: "Así, en Colombia durante las primeras décadas del siglo XX, el discurso eugenésico entra como plan, como propuesta y como ámbito de saber, y paulatinamente se va consolidando, gracias a la intelectualidad de comienzos del siglo XX, en una especie de política nacional". 30

En consecuencia, si se somete al Cancionero a un análisis más atento y se hace una lectura no solo musical, sino histórica y ético-política de sus textos, se advierte cómo el proyecto eugenésico cultural somete a procesos de blanqueamiento a las prácticas musicales de pueblos originarios, afrocolombianos y campesinos. De esta manera, se despoja a las nuevas reelaboraciones de dichas influencias que han sido desaprobadas por la construcción de ciudadanía y nación colombiana. Es así como

Egberto Bermúdez, “¿Qué es el vallenato? Una aproximación musicológica”, Ensayos. Historia y Teoría del Arte 9.9 (2004): 59.

26. Véase Cancionero escolar (Bogotá: Biblioteca Aldeana de Colombia, 1935) I.

27. José Ignacio Perdomo, Historia de la música en Colombia (Bogotá: Plaza y Janes Editores, 1980) 125.

28. Perdomo 9.

29. Darío Blanco, "La música de la Costa Atlántica colombiana. Transculturalidad e identidades en México y Latinoamérica”, Revista Colombiana de Antropología 41 (2005): 174

30. Andrés Runge y Diego Muñoz, "Actividad vs. agitación en el pensamiento de Luis López de Mesa: Relaciones entre pedagogía y eugenesia en la Colombia de principios del siglo XX", Revista Colombiana de Educación 1.61 (2011): 23, 33. 
lo que les queda es asumir formas que les permitan mimetizarse, con el fin de ser aceptadas por grupos sociales con las cuales, ya blanqueadas, se generan nuevos procesos de construcción de identidad; estos grupos sociales son principalmente las élites y la Iglesia católica. ${ }^{31}$ En este sentido, en el Cancionero pueden advertirse estos procesos desde dos perspectivas interrelacionadas: ${ }^{32}$ la primera de ellas apunta hacia la acción catequética y civilizadora que ha venido desempeñando la Iglesia desde la "conquista", y que junto con el Estado continuó ejerciendo en el siglo XX (acción catequética de la cual no escapó la formación musical), y la segunda se desarrolla mediante el establecimiento de un sistema (musical) de diferencias jerárquicas basado en el color de la piel, ${ }^{33}$ inferido en la categorización epistémica "negro" e "indio" 34 y sus prácticas musicales.

\section{4. "Ave Maris Stella”, "O Salutaris Hostia"}

Desde la primera perspectiva, en el Cancionero escolar se encuentran respectivamente "Ave Maris Stella" (un texto del siglo IX de adoración a laVirgen María) y "O Salutaris Hostia", (usado para la Adoración al Santísimo Sacramento, de Santo Tomás de Aquino). ${ }^{35}$ Ambas canciones permiten percibir cómo en el espacio de la pedagogía musical, promovido por la campaña de Cultura Aldeana y Rural de 1934 y materializado en la publicación del Cancionero al año siguiente, la Iglesia católica continuó inalterablemente ejerciendo su autoridad. Situación que se estableció por las prerrogativas cedidas por el Estado desde el concordato de 1887 en el cual se le otorgó a la Iglesia católica un inmenso poder, ${ }^{36}$ del que no escapó la construcción de los proyectos político-educativos. Esta autoridad, al parecer, además, fue legitimada por tesis como la expuesta por el propio López de Mesa en su manuscrito "Cristianismo y política", en el que destaca la histórica confluencia benefactora que ha existido entre las dos tendencias: entre el cristianismo y la

31. Blanco realiza una importante analogía con la música vallenata.

32. Biblioteca Aldeana de Colombia 2, 6 y 23-25.

33. Cristina Rojas, Civilización y violencia. La búsqueda de la identidad en la Colombia del siglo XIX (Bogotá: Pontificia Universidad Javeriana, 2001) 71.

34. Walter Mignolo afirma que "primitivo, bárbaro y el otro no son categorías ontológicas, sino epistemológicas, inventadas por y en la civilización occidental [es decir] contada por la mitad de la historia". Walter Mignolo, Habitar la frontera. Sentir y pensar la descolonialidad (Antología, 1999-2014) (Barcelona: CIDOB / Universidad Autónoma de Ciudad Juárez, 2015) 442-443. En este sentido y teniendo en cuenta que los procesos civilizatorios de principios del siglo XX en Colombia se arraigan en las ideas modernas de progreso, civilización y de construcción de una identidad nacional, las categorías de indio y negro pasan a ser también categorías epistemológicas y no ontológicas, ideologizadamente construidas por la historia que ha sido escrita por las élites y por la Iglesia católica.

35. Cancionero escolar 2 y 23-24.

36. Álvaro Tirado Mejía, "Colombia. Siglo y medio de bipartidismo", Colombia Hoy, coord. Jorge Orlando Melo (Bogotá:Tercer Mundo Editores, 1995) 127. 
política. ${ }^{37}$ Por otro lado, Ignacio Perdomo justifica esta injerencia de la doctrina cristiana en las prácticas musicales y pedagógico-musicales al manifestar que "Felipe II en sus Ordenanzas aconseja que donde la doctrina cristiana se enseñe, los sacerdotes en ayuda de su misión podrán usar de música de cantores y de ministriles altos y bajos"”. De igual forma, destaca el reforzamiento de la acción catequética y civilizadora de la iglesia a través de la música al afirmar: "Atractivo sin par, definitiva influencia desplegó la música de Iglesia en la labor civilizadora y misionera que los doctrineros llevaron a cabo para atraer neófitos a la fe católica" 38

\section{A mí me gusta lo blanco, muera lo negro y así el indiecito va tocando su tambor...}

Por otro lado, desde la segunda perspectiva, se encuentra una melodía que lleva como título A mí me gusta lo blanco, y otra titulada Indio. El primer contenido expresa: "A mí me gusta lo blanco, viva lo blanco, muera lo negro que lo negro es cosa triste, yo soy alegre, yo soy alegre”. ${ }^{39}$ Barriga Monroy llama la atención al decir que: “A fines del siglo XIX y principios del XX, durante el período 1880-1920, cuando apareció la modalidad de educación musical formal, los afro-descendientes fueron excluidos de ésta nueva modalidad, por cuanto para matricularse en las academias y escuelas de música se les exigía la partida de bautizo, el registro de matrimonio, y la presentación de un fiador entre otros requisitos". ${ }^{4}$

Además, se puede apreciar que "dentro del currículo de música en las escuelas públicas se enseñaban diversas canciones a los niños, tomadas de cancioneros europeos, con contenido claramente racista". ${ }^{41}$ En efecto, se debe considerar que el Cancionero no fue ajeno a las transformaciones sociales de la época y a los discursos eugenésico-pedagógicos y eugenésico-culturales que fueron impulsados por las élites colombianas. Se podría decir que también el repertorio del Cancionero sometió a los pueblos originarios, a los afrodescendientes, zambos y mestizos, de los cuales se desprende también la tambora chimichagüera, a la misma discriminación de la que fueron objeto en el espacio social, tal como lo manifiestan Runge y Muñoz:

37. Luis López de Mesa, “Cristianismo y política”, Medellín, s.f. BCGD, Medellín, Archivos Personales, Luis López de Mesa (LLM), Carpeta 20-1, Documento 305, ff. 147-148. Llama la atención que, según Runge y Muñoz, López de Mesa hizo parte de la variante sociologista Laica de la Escuela Nueva, no obstante, surge el interrogante de qué tan lejana estaba dicha laicidad de la iglesia católica al permitir la incorporación de repertorio musical católico al Cancionero.

38. Perdomo 18.

39. Cancionero 6-7.

40. Martha Barriga, "El afro-colombiano en la educación musical desde la Colonia hasta principios del siglo XX”, El Artista 9 (2012): 346.

41. Barriga 347. 
En Colombia los defensores de la ideología del progreso y de los programas de perfeccionamiento con sus ideales de formación encontraron como polo opuesto, como asunto por combatir, el problema de la degeneración de la raza y la situación infantil de la sociedad, pero, de un modo particular, la situación de ciertos grupos (negros, indígenas, clases populares). Se tenían grandes esperanzas en que los saberes modernos iban a ayudar, en nombre del progreso y de la modernización, a mejorar no solo las condiciones materiales, sino sociales, culturales y espirituales de una población que se consideraba como "raza enferma". ${ }^{42}$

Por tanto, al ser improcedente desarticular las prácticas humanas de las prácticas discursivas de los pueblos originarios y afrodescendientes mencionados, se debía aceptar acríticamente que tales grupos sociales o "razas enfermas" carecían de toda posibilidad de nombrar como música a sus manifestaciones sonoras y corporales equivalentemente "enfermas". Tal vez por esto, para los discursos oficiales de la época entre 1930-1946, estas manifestaciones artísticas no alcanzaron a tener el estatus de folclor a diferencia de las músicas andinas y posteriormente la cumbia. ${ }^{43}$

\section{Entre músicas melancólicas y cantos tristes del infierno}

Con relación a las músicas de los pueblos originarios de Colombia, Luis López de Mesa en la conferencia leída ante la Academia de Bellas Artes de Colombia, en 1931, pronunció lo siguiente:

ni de otra manera ocurre en el desenvolvimiento histórico de la música. El alma de los primitivos, estructurada en unas decenas de hábitos rudamente simbólicos, uraña, sufrida y aherrojada a un fatalismo irrecusable, se expresa en ritmos de tosca consonancia y en la melodía quejumbrosa de su canto. ¿YY qué más triste sobre la haz de la tierra que ese canto? Es como si el hambre y el frío, el castigo injusto y la traición se enlazaran en un trémolo de desolación crepuscular. ${ }^{44}$

42. Runge y Muñoz 47-48.

43. López de Mesa reconocía como folclor únicamente a tres aires andinos colombianos y a la cumbia. López de Mesa, "Expresión artística del pueblo colombiano. De como se ha formado la nación colombiana. Primera parte", Medellín, [s.f.]. BCGD, Medellín, Archivos Personales, LLM, C12, D222, f. 7; Luis López de Mesa, "Música”, Medellín, [s.f.] BCGD, Archivos Personales, LLM, C12-1, D226, f. 146. Cuando Perdomo escribe sobre cultivadores del folclor se refiere principalmente a personajes como Emilio Murillo, véase Perdomo 235. Sin embargo, el historiador Héctor Rendón precisa que Murillo se destacó por ser uno de los creadores de las estudiantinas y difusor de las músicas de cuerda colombianas en el exterior (no de tambora chimichagüera); véase Héctor Rendón Marín, De liras a cuerdas. Una historia social de la música a través de las estudiantinas. Medellín 1940-1980 (Tesis de Maestría en Historia, Universidad Nacional de Colombia, sede Medellín, 2009) 51.

44. Luis López de Mesa, "La Conferencia Leída ante la Academia de Bellas Artes de Colombia en su primera sesión pública 1931”, Medellín, 24 de abril de 1931. BCGD, Archivos Personales, LLM, C31-1, D493, f. 181. 
Estas adjetivaciones de primitivo, cantos melancólicos y tristes se encuentran también en las descripciones hechas por Perdomo sobre los Chibchas: "cantaban al son de unas flautas o fotutos tan melancólicos y tristes que más parecían música del infierno que de este mundo", y en el mismo sentido continúa más adelante, "La música indígena colombiana parece estar desprovista de realismo y de estética; se nota la ausencia de motivos aprovechables, se caracteriza por el estado primitivo y rudimentario que se nota en los principios de la historia de la música". ${ }^{45}$

En este orden de ideas, la segunda melodía anónima del Cancionero escolar responde precisamente al nombre de "Indio", y su contenido expresa: "Así el indiecito va tocando su tambor". ${ }^{46}$ En primer lugar, la categoría epistémica de "indio" como construcción ideológica erguida por parte de las élites colombianas hacia el ser, el saber y el hacer musical de los pueblos originarios fue ampliamente utilizada tanto por intelectuales como López de Mesa, y otros liberales ${ }^{47}$ iniciadores de las reformas culturales que propuso La Revolución en Marcha, como por historiadores de la música colombiana como José Ignacio Perdomo. La finalidad del uso de la categoría "indio" era invisibilizar cualquier posible aporte que pudieran hacer al "ideal" de la cultura musical colombiana. Ahora bien, sobre sus instrumentos musicales, principalmente el tambor, López de Mesa hizo la siguiente afirmación: "Los indígenas americanos de esta parte del Continente no dejaron una tradición musical definible. La escala pentatónica de los Incas es pobre para informar obra de grande aliento: y en dilatadas extensiones del Nuevo Mundo nunca pasó ese arte de la mera percusión rítmica, [...] el guaraná y el tambor [...] no bastan para instrumentar un elevado tema", 48

Por su parte, Ignacio Perdomo acentuó el primitivismo de los instrumentos musicales y las danzas de los pueblos originarios, posiblemente sin comprender sus formas de percibir el arte y la música, cuando declara que: "La música de los indios colombianos acompañaba sones primitivos y salvajes danzas". Además, según su criterio y en coincidencia con la "situación infantil de la sociedad colombiana" descrita por Runge y Muñoz, los pueblos como el "indio" también "se encontraban en infancia musical a la llegada de los españoles a América". ${ }^{4}$

En resumen, algunas piezas del Cancionero escolar, como las anteriormente descritas, reforzaron el proyecto de eugenesia cultural en las primeras décadas del

45. Perdomo 8, 9 .

46. Biblioteca Aldeana de Colombia 25.

47. Pedro Fermín de Vargas comentaría sobre los "indios": "Para expandir nuestra agricultura habría necesidad de hispanizar a nuestros indios. Su ociosidad, estupidez e indiferencia hacia los esfuerzos humanos normales nos llevan a pensar que provienen de una raza degenerada que se deteriora en proporción a la distancia de su origen [...] sería muy conveniente que se extinguieran los indios, mezclándolos con los blancos". Citado en Benedict Anderson, Comunidades imaginadas. Reflexiones sobre el origen y la difusión del nacionalismo (México: Fondo de Cultura Económica, 2013) 32.

48. López de Mesa, "Expresión Artística del Pueblo colombiano. De como se ha formado la nación colombiana. Segunda parte”, Medellín, [s.f.]. BCGD Archivos Personales, LLM, C12, D222, f. 21.

49. Perdomo 9. 
siglo XX, mediante el blanqueamiento de las prácticas musicales de los grupos humanos percibidos como la "raza enferma". Estos grupos que se consideraban muy aficionados a la música, ${ }^{50}$ pero sin saber nada de ella, según Perdomo, fueron vulnerables al adoctrinamiento en el canto gregoriano, en la predicación del evangelio o en la interpretación instrumental, y presentaron un desarraigo imperceptible pero violentamente simbólico. Perdomo recordaría el importante papel de la Iglesia en esta función: "Enseñaron a los indios intérpretes algo de canto eclesiástico para dar más solemnidad al culto, y como éstos iban asimilándolo, al cabo de cierto tiempo ya sabían algunos extractos del kyrial y jaculatorias cantadas". ${ }^{51}$

Agrega Perdomo que:

Los ejemplos pueden multiplicarse [...] [San Francisco Solano] muchas veces para atraer a los indios nómades $[\ldots]$ pulsaba diestramente un violín y cantaba férvidos religiosos cantos. Y los indios atraídos y cautivados como por magnética misteriosa fuerza le rodeaban atónitos; entonces dejando el instrumento, empuñaba el crucifijo y al canto sagrado sucedía la catequesis religiosa. ${ }^{52}$

Este esfuerzo por invisibilizar y borrar las creaciones de las culturas originarias $\mathrm{y}$ afrodescendientes, al igual que posiblemente lo hizo el Cancionero desde la pedagogía musical, desterró del imaginario de los niños colombianos y de las tradiciones comunes las manifestaciones de la tradición oral. Se coincide así con Barriga Monroy en que la historia oficial del arte y la música en Colombia facilitó que se invisibilizaran todas aquellas prácticas orales que la "otra" sociedad colombiana conformada por "indios", "negros" y poblaciones rurales había creado antes de la conformación del Cancionero. Prácticas orales y artísticas que fueron excluidas por el Cancionero como es el caso, entre muchos otros, de "Candela viva" de Heriberto Pretel. ${ }^{53}$ No se quiere decir con esto que no se hayan dado importantes procesos de sincretismo cultural a partir de los cuales el cantador de tambora modeló sus creencias y sus prácticas, tal es el caso de Pretel y su Divina Pastora (Figura 1). ${ }^{54}$ En realidad, lo que se pretende, más bien, es plantear desde un enfoque de territorio las implicaciones promovidas por la negación de la reproducción de las músicas que construyeron entramados musicales comunitarios complejos, y que a través de la transmisión oral resistieron el embate del proyecto eugenésico-cultural y musical.

\section{Perdomo 20.}

51. Perdomo 18.

52. Perdomo 18.

53. Dice la investigadora "Las canciones compuestas por afro-descendientes e indígenas durante el período 1880-1920, aún son desconocidas y no fueron incluidas en los cancioneros para la enseñanza musical de los niños en la escuela formal". Barriga 353.

54. La Figura 1 es el único registro fotográfico de Heriberto Pretel con que cuenta la comunidad musical de Chimichagua. En ella sostiene en sus manos a La Divina Pastora. Una pequeña piedra con la figura tallada de una Virgen que fue encontrada por la familia de Heriberto en 1899. Medina, Mi Chimichagua 68-69. 
Figura 1. Heriberto Pretel

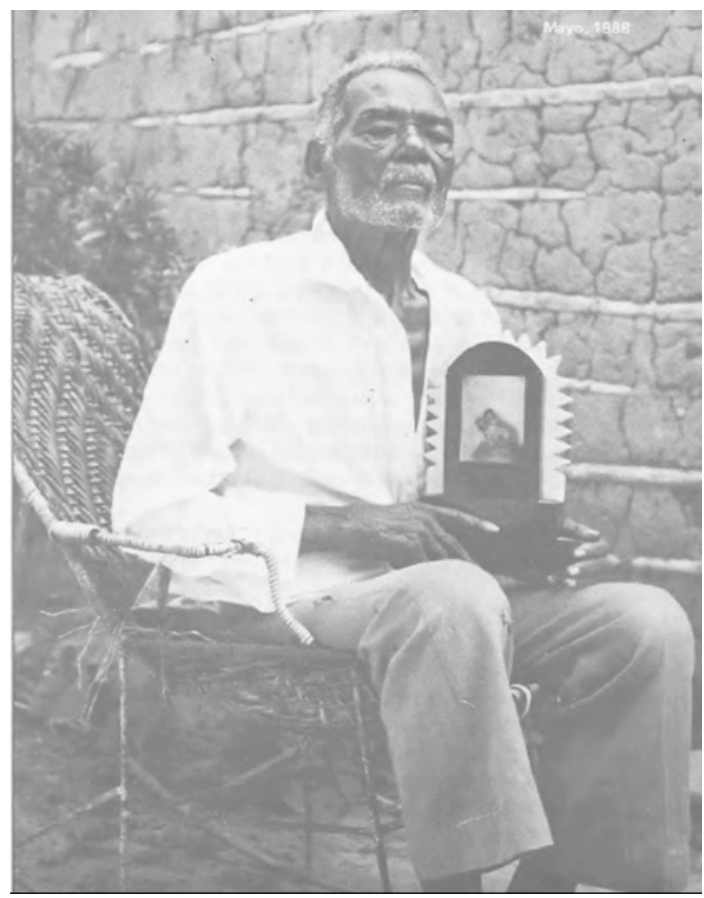

Fuente: Ismael Medina, “Heriberto Pretel y su 'Divina Pastora', Chimichagua, 1988”, Mi Chimichagua de ayer (Cali: Arte Libro Impresores, 1990).

\section{El Cancionero en Chimichagua y la Encuesta Folclórica Nacional}

En el rastreo realizado en Chimichagua los cultores manifestaron no conocer el Cancionero de la Biblioteca Aldeana de Colombia, por su parte, en el archivo municipal no aparecen documentos sobre peticiones hechas por el alcalde de aquella época, ni en la Biblioteca Nacional, ni en el Ministerio de Educación como era costumbre. Esta ausencia puede obedecer a que, como lo afirmó Silva, el proyecto de Cultura Aldeana no obtuvo los resultados esperados, ${ }^{55}$ además, entre otros factores, posiblemente dicho proyecto educativo al carecer de conocimiento sobre los saberes previos de la comunidad musical y como reflejo de dicho desconocimiento en la elección del repertorio musical, carecía de una matriz dialógica y contextual, lo que hacía a la propuesta ser ajena a las sensibilidades y percepciones de los detentores.

En Chimichagua, por ejemplo, así como en el resto de la ciénaga de Zapatosa, al ser un espacio habitado por descendientes de pueblos originarios, como los lecturas durante la república liberal: Colombia, 1930-1946”, Revista Sociedad y Economía 3 (2002): 147. 
Chimilas, Arhuacos, Koguis, Wiwas, Kankuamos, Yukos y Bari Motilones, y de pueblos afrodescendientes ${ }^{56}$ el Cancionero no propuso un modelo de enseñanza musical coherente, sino más bien un modelo impositivo. No se tuvo en cuenta que este municipio es portador de diversidad de cantos entre los que se encuentra la tambora, las rondas y los juegos infantiles también transmitidos de generación en generación a través de la oralidad como sistema de transmisión musical principalmente pragmático, ${ }^{57}$ onomatopéyico ${ }^{58}$ y rítmico-perceptivo, ${ }^{59}$ y cuyos desarrollos han sido validados por las comunidades. Ahora bien, tampoco se pretende desconocer con estas apreciaciones la intención política que había por resaltar la importancia de la cultura popular colombiana. Intención loable que según el propio Silva "se mantuvo, y a principios de los años cuarenta la vemos reaparecer con toda su fuerza en las "misiones culturales", 60

Para no desbordar los límites del texto, no se aproximarán reflexiones sobre las misiones culturales por considerar a la Encuesta Folclórica Nacional como el momento histórico al cual se pretende llegar, no obstante lo anterior, es necesario formular algunas preguntas, sobre todo cuando Silva aduce que "el proyecto nacional de los intelectuales liberales [...] representaba una nueva actitud de revaloración de lo popular, enfocada a la transformación de las condiciones sociales y culturales de las zonas rurales colombianas". ${ }^{61}$ En este sentido, cabe preguntarse entonces ¿a qué tipo de transformaciones hace referencia? Y si estas ¿emergen en principio de una lectura holística y multipreposicional ${ }^{62}$ de los territorios? Estas

56. Según la caracterización departamental del Plan de Desarrollo del departamento del Cesar 20162019, ha sido declarado como territorio diverso y multiétnico. Gobernación del Cesar, "Plan de Desarrollo. Departamento del Cesar 2016-2019. El camino hacia la paz" (Documento oficial, Gobernación del Cesar, 2016) 14.http://cesar.gov.co/d/filesmain/plan_desarrollo/plan_de_desarrollo_departamental_2016-2019_el_camino_del_desarrollo_y_la_paz.pdf (09/10/2017).

57. "Los jóvenes aprenden de los ancianos por tradición oral, es decir, no nombran la tambora y los sones por tratarse $[\ldots]$ de constructos teóricos, lo hacen porque para ellos el hecho de nombrar, está vinculado a la ejecución de la tambora in situ, [...] como fenómenos relacionados con la transmisión de los saberes de las comunidades con respecto a los valores de la música". Bernardo A. Ciro Gómez y Jhon Eduard Ciro Gómez, "Etnografía musical en el río Magdalena. El son de Berroche de la subregión de Loba", Periferia 20.2 (2015): 150.

58. Sonidos que reproducen los músicos al imitar los golpes en los cueros o en la madera de una tambora. Estos sonidos ayudan a los tamboreros y cantadores a distinguir los acentos y los no acentos musicales.

59. Los músicos de tradición oral aprenden escuchando a otros ejecutar los ritmos. Al respecto, el musicólogo Humberto Sagredo, basado en los postulados de la Gestalt, propuso una revisión a la teoría del ritmo afirmando que este tiene varios niveles perceptivos, y que en estos niveles los acentos y no acentos son muy importantes. Lo que significa que, más allá de la partitura musical, los músicos de tradición oral perciben una serie de partes acentuadas y no acentuadas que les permite reconocer musicalmente a la tambora. Humberto Sagredo, "El ritmo en la música venezolana", Revista Musical de Venezuela 25 (1988): 47-107.

60. Silva, "Encuesta Folclórica Nacional, 1942 (Instrucciones)" 10.

61. Silva, "Encuesta Folclórica Nacional, 1942 (Instrucciones)" 7.

62. El autor del presente texto propone lo multipreposicional entendido como una matriz partici- 
inquietudes se plantean en el contexto de los datos obtenidos por la Encuesta Folclórica Nacional de 1942, como el tercer y último proyecto de los intelectuales liberales colombianos y que Silva presentó en uno de sus escritos.

Como puede observarse, en 1942, cuando se realizó la Encuesta Folclórica Nacional todos los municipios que actualmente conforman la ciénaga de Zapatosa pertenecían al Magdalena Grande hasta que se expidió la Ley 25 de 1967, con la que fue creado el departamento del Cesar. Si a lo anterior se suma que en el Magdalena Grande se realizaron 2 encuestas de 288 diligenciadas (menos del 1\%) y que el total de encuestas fueron 1,000 a nivel nacional ${ }^{63}(0.2 \%)$ de las cuales, según Silva ambas fueron remitidas pero una de ellas se diligenció de forma incompleta $(0.1 \%)$, se demuestra un desalentador panorama de las investigaciones folclóricas y los registros documentales tanto de las músicas como de los cantadores como Heriberto Pretel. ${ }^{64}$ Además, como Pretel no tuvo derecho a pensión, a salud u otro beneficio del Estado, no se tuvo acceso a documentos personales que permitieran hacer algún tipo de rastreo.

\section{El fracaso de la Encuesta Folclórica Nacional y la emergencia de la industria musical}

Desde esta perspectiva, Silva atribuye parte del fracaso a la falta de orientación por parte del proyecto, al ambiente de indiferencia institucional existente después de 1946 y a la poca estima que se tenía a la entonces Comisión Nacional de Folclor. ${ }^{65}$ Fracaso que sucedía en un momento histórico significativo para el conocimiento y reconocimiento de las músicas de tradición oral y de sus detentores en cada subregión. No se buscó indagar en ningún sentido sobre las significaciones sonoras, la configuraron social de sus circuitos tradicionales de transmisión y sus estrategias de divulgación, además, tampoco se preguntó sobre la multiplicidad de comprensiones rítmico-perceptivas, del papel político de los versos cantados y su materialización en discursos identitarios y, menos aún, de los espacios participativos e intercomunitarios donde aquellos grupos humanos productores y receptores de esta música que aun estando en diferentes lugares geográficos se identificaban entre sí con la tambora. Fue así como se perdió la oportunidad de que a partir de estas músicas se creara una comunidad musical imaginada que, como decía Anderson con la idea de nación, "a pesar de la desigualdad y la explotación comporte un compañerismo profundo y horizontal". ${ }^{66}$

pativa para los territorios, con los territorios, desde y entre los territorios.

63. Renán Silva, "Encuesta Folclórica Nacional, 1942. Presentación de la Encuesta y esbozos de un primer resultado", Anuario de Investigaciones de la Universidad del Valle (2001): 376.

64. A pesar de que estos cantadores fueron referentes musicales de la tambora de Chimichagua desde 1910 no se encontraron documentos notariales, porque según la notaría Única de Chimichagua esos documentos desaparecieron al momento en que se creó el departamento.

65. Silva, “Encuesta Folclórica Nacional. 1942. Presentación” 376.

66. Anderson 25. 
El establecimiento de este tipo de preguntas pudo haber brindado herramientas para comprender el impacto que sobre la formación del gusto estableció la industria musical, tras su incursión en estos territorios en los mismos años donde se diluyeron las expectativas creadas por la Encuesta Folclórica Nacional. Para entender lo anterior se debe tener en cuenta que en las conversaciones con los dos referentes tamboreros de Chimichagua, Juan Robles y Dolores "Lole” Pretel, con 86 y 84 años, respectivamente, en el momento de las entrevistas permitieron vislumbrar situaciones que al relacionarlas con los datos, demuestran los posibles impactos de la industria musical sobre la tambora chimichagüera, vistos desde el lugar de enunciación de dos músicos de tradición oral.

-Bernardo Ciro (BC): Don Juan ¿tocó usted con don Heriberto?

-Juan Robles (JR): Sí, en la caja, él era el rey aquí de la tambora [...] la mayoría de las tamboras chimichagüeras fueron compuestas por Heriberto Pretel.

-BC: ¿y cuándo se empieza a escuchar menos la tambora en Chimichagua?

-JR: estos bailes antiguos y lo que era la diversión, eso se comenzó a agotar cuando empezó a haber música grabada, porque anteriormente no había [...] cuando ya comenzó a haber la música grabada ya no le paraban bolas a los decimeros, ya también se fue acabando la gente que le gustaba la vaina de los tambores.

-BC: ¿recuerda el año en que dejó de escucharse la tambora?

一JR:Eso fue por ahí en el año 50 que comenzó a mermar, lo que eran las fiestas de la tambora. ${ }^{67}$

Por su parte, Dolores Pretel dijo:

—BC: Don Dolores ¿Qué recuerda usted sobre la tambora?

-Dolores Pretel: Aquí yo era el que tocaba, aquí no tocaba más nadie [...] cuando Cecilio Robles murió [en 1974] [...] Yo dejé la tambora tempranito, me gustaba más el vallenato que la tambora porque con el vallenato ganaba uno más plata que haciendo presentaciones con la tambora. ${ }^{68}$

\section{La industria musical y el cesar de los tambores y los cantos}

Hasta aquí se puede inferir que la confluencia entre el declive de la Encuesta Folclórica Nacional, las escasas investigaciones de campo hacia las músicas de tradición oral ${ }^{69}$ y la consolidación de la industria musical a mediados de los años 40, así como su relación con la reproducción de nuevas subjetividades, permitió

67. Entrevista de Bernardo A. Ciro a Juan Robles, Chimichagua, Cesar, 21 de noviembre de 2017.

68. Entrevista de Bernardo A. Ciro a Dolores Pretel, Chimichagua, Cesar, 23 de noviembre de 2017.

69. Silva afirmaría: "el olvido en que después de 1946 cayó el proyecto cultural del liberalismo, el que fue sustituido por iniciativas diferentes en las que poco eco encontraba la investigación de las sociedades campesinas bajo la óptica que había diseñado la República Liberal". Silva, "Encuesta Folclórica Nacional, 1942 (Instrucciones)" 18. 
el desarrollo de un escenario regresivo para la tambora chimichagüera. A partir de los años 1940-1946, algunos músicos de diferentes partes de la costa Caribe colombiana habían blanqueado su música con el interés de entrar en los espacios y los gustos de la élite del interior del país. ${ }^{70}$ De esta forma, llama la atención cómo las políticas culturales del Estado a través de la fallida Encuesta Folclórica Nacional concedieron un espacio político e histórico a la industria musical para la reelaboración de una nueva historia de la música costeña. Esta condición hacía ahora posible su consumo como una música alegre, comunitaria y pacífica con la que se trataría de ocultar los horrores de la guerra desatada por dichas élites; ${ }^{71}$ asimismo, este blanqueamiento musical determinó que desde finales de la década de 1940 la historia de campesinos que fueron referentes de la música de tradición oral como Pretel y los músicos que lo acompañaron, cuya música fue creada en torno a hechos sociales vividos por la comunidad, se invisibilizara hasta aparecer como no existentes. ${ }^{72}$

\section{Tan cantador que era yo y todo se acaba...}

En este sentido, Hernán Martínez recordaría unas palabras de la esposa de Cecilio Robles, uno de los últimos tamboreros y compañero inseparable de Pretel:

Cuando él se murió ya anciano en 1974 [Cecilio Robles], dijo la señora de él: mano nancho, yo le voy a recomendar, no deje morir la tambora.Y yo tuve que irme a estudiar y hubo un lapsus de 15 a 20 años en que aquí en Chimichagua no se escuchaba la tambora, desde que murió él, diríamos que, con Heriberto ya aislado en Plata Perdía, fueron el último eslabón y no se escuchó más la tambora... se murió. ${ }^{73}$

70. Peter Wade afirma que: "muchos músicos costeños se conectaron estrechamente con músicos blancos del interior; y en este sentido, y por medio de las orquestaciones, se dio un proceso de blanqueamiento de la música costeña urbana y comercial, perceptible en comparación con aires rurales o con otros aires urbanos costeños”. Peter Wade, Música, raza y nación. Música tropical en Colombia (Bogotá:Vicepresidencia de la República, 2002) 180-181.

71. Wade afirma "la región costeña se presentaba como bastante pacífica y esto contribuyó a reforzar otra lectura posible de la región, la de un lugar donde todavía reinaban valores comunitarios tradicionales [...] la música costeña tal vez refleje un escapismo urbano que se solazaba con el crecimiento económico del período, le daba la espalda al conflicto interno y se proyectaba hacia un mañana brillante con raíces en una moralidad comunitaria y pacífica". Wade 180-181.

72. Para el año 1992, el investigador Tomás D. Gutiérrez, aunque mencionó las composiciones atribuidas a don Heriberto, desconoció su autoría. Además, según su percepción, asume que la tambora "antes de sumergirse en el olvido, le legó su estructura [...] rítmica al vallenato". Tomás Gutiérrez, Cultura vallenata. Origen, teoría y pruebas (Bogotá: Panamericana, 2014) 369.

73. Entrevista de Bernardo A. Ciro Gómez a Hernán Martínez, Chimichagua, Cesar, 27 de noviembre de 2017. 
Pretel vivía de los pocos productos que cultivaba en su pequeña parcela y de las limosnas que las personas le dejaban como ofrenda a la "Pastorita". ${ }^{74}$ Cuando Medina Lima lo visitó en mayo de 1988 lo encontró muy enfermo. Al decirle que cantara una tambora como "Candela viva", Pretel, posiblemente recordando cuando cantaba en las correrías de la ciénaga con sus viejos amigos y tamboreros, le respondió: "Uhhh tan cantador que era yo [...] y todo se acaba [...] No, oyera el tambor sí lo recordaba. A mí me alegraba era el tambor [...] yo cantaba era por el son del tambor, íbamoj al compá el tambor conmigo, pero yo solo así, sin tambor, no" 75

\section{Conclusiones}

Paralelo a los proyectos culturales impulsados por la Revolución en Marcha como fueron la campaña de Cultura Aldeana y Rural, las bibliotecas aldeanas y la Encuesta Folclórica Nacional, entre los años de 1930 y 1946 en Colombia hubo una significativa cantidad de entramados comunitarios de resistencia, cuyas expectativas de transformación social y cultural, al parecer opuestas a las planteadas por dichos proyectos culturales, fueron desactivadas históricamente al fracasar, en términos prácticos y políticos, la Encuesta Folclórica Nacional. De esta manera, la expresión musical de estos entramados comunitarios de resistencia fue invisibilizada por la gestión homogeneizante de la reproducción subjetiva, propia de los mecanismos de la industria musical que en buena medida dirigió el reconocimiento mediático hacia manifestaciones como el vallenato, al cual otorgó el estatus de representatividad en una nación con multiplicidad de prácticas culturales igualmente importantes.

En un breve ejemplo, como dice Levi, si se hace una "revisión microscópica de la historia" de algunos de los hechos que posiblemente incidieron en dicho reconocimiento mediático a la manifestación del vallenato, y a uno de sus principales representantes como lo fue Alejo Durán, podrían identificarse dos escenarios. El primero corresponde a la politización de la difusión del vallenato "apropiado por la élite social y política de Valledupar"76 como demarcación identitaria de un departamento recientemente creado. Por su parte, el segundo escenario corresponde a la reapropiación y transformación de las melodías de la tambora del sur del departamento del Cesar ante la indiferencia de dichas élites sobre esta práctica en esta zona. Con referencia al primer escenario histórico, cabe destacar que la creación del mencionado departamento y las dinámicas de divulgación de la denominada cultura popular implementadas por el Instituto Colombiano de Cultura le permitieron al vallenato configurarse como "el género que mayor atención

74. Medina, Mi Chimichagua 99.

75. Medina, Chimichagua 70.

76. Egberto Bermúdez, “Jacques Gilard y la música popular colombiana”, Caravell 93 (2009): 20. 
[ha recibido] por parte de la industria musical y los medios de comunicación". ${ }^{77}$ En este sentido, ocupa un lugar muy importante la participación de destacados intelectuales costeños como Gabriel García Márquez y personajes como Alfonso López Michelsen y Consuelo Araujo, quienes, como indicaría Bermúdez "con un poco de ayuda de sus amigos políticos y literatos y utilizando los grandes medios masivos de comunicación (prensa, radio, televisión e industria fonográfica)", ${ }^{78}$ lograron posicionar la tradición vallenata; esa que según Jacques Gilard "no es más que el estadio alcanzado por esa música cuando la atrapó el engranaje de la comunicación moderna masiva" ${ }^{79}$

Asimismo, la antropóloga Gloria Triana jugó un papel muy importante como asesora de la oficina de festivales y folklore del Instituto Colombiano de Cultura en los años ochenta. Triana conoció a Durán en la ciudad de Bogotá, ${ }^{80}$ ella fue la encargada de posicionarlo en los medios de comunicación de la época (televisión y radio), y por ende en la memoria de todos los colombianos, a través del programa Yuruparí y del documental "Los últimos juglares y el nuevo rey", grabado en El Paso, Cesar, en 1985. Paradójicamente, cerca de este lugar se encontraba Heriberto Pretel, y al igual que lo sucedido con el declive de la Encuesta Folclórica Nacional y las expectativas de conocer a profundidad las manifestaciones de tradición oral colombianas en los años cuarenta, permaneció oculto al lente de Yuruparí en los años ochenta. Murió don Heriberto y los tambores y los cantos de Chimichagua cesaron. No se busca decir con esto que Heriberto pudo haber sido el más popular cantador de tambora en Colombia, si el lente de Yuruparí hubiese narrado su historia, más bien, se llama a reflexionar sobre la importancia que podría representar un giro multidireccional de ese lente que ha homogeneizado las percepciones y ha facilitado la negación de lo que no visibiliza.

De esta forma, lo no visible estatalmente como Heriberto Pretel, perteneciente a la cultura rural de Chimichagua, se convierte en una alegoría del cantador de tambora de toda la Depresión Momposina. Así como Pretel, hay otros y otras cuyos cantos han cesado para ser escuchados en la voz de los otros y de las otras que todavía divulgan su legado, en personas como Daniel Palmera, Leocadia Ortiz, Hernán Martínez y Héctor “Chichi” Rapalino; asimismo, gracias a los dilemas de la cultura, son recordados porque sus nombres son utilizados para designar representativas edificaciones y Casas de la Cultura, aunque considerados "incultos", o de los auditorios y bibliotecas, aunque considerados "analfabetas"

77. Egberto Bermúdez, “¿Qué es vallenato? Una aproximación musicológica”, Ensayos. Historia y teoría del arte 9.9 (2004): 14.

78. Bermúdez, "Jacques Gilard" 20.

79. Jacques Gilard, “Vallenato. ¿Cuál tradición narrativa?”, Huellas. Revista de la Universidad del Norte 19 (1987): 59-68.

80. María Elvira Talero, coord., "Gloria Triana”, Cinemateca. Cuadernos de Cine Colombiano 24 (1987): 13-14.

81. Don Heriberto murió en la extrema pobreza, sin una pensión o ayuda económica del gobierno municipal. Años después, el municipio de Chimichagua construye un importante Centro de Convenciones llamado "Heriberto Pretel". 
En este sentido, la microhistoria con sus lecturas de lo extra-musical ${ }^{82}$ podría ampliar el prisma de las investigaciones a partir de las músicas de tradición oral que se hacen desde las artes y la música académica.

En el caso del segundo escenario histórico que corresponde a la reapropiación y a la transformación de la tambora a paseo vallenato, algunos investigadores como Quiroz $^{83}$ y Gutiérrez han intuido una condición primitiva de la misma, a lo que otros cultores de la tambora, como Diógenes Pino del municipio de Tamalameque, responden:

No, por eso cuando me invitan como ponente a eventos en Valledupar, trato de decirle a mis hermanos del norte que lo que nos identifica a los pueblos del sur del Cesar, Bolívar y Magdalena es la tambora y no el vallenato, así que no es posible que el vallenato sea una evolución de la tambora o que la tambora haya desaparecido. ${ }^{84}$

Con respecto a esta transformación, que como explicación matiza un poco la figura de genio creador concedida a Durán por parte de los mencionados investigadores, el compositor chimichagüero Lucho Cadena dice:

La tambora de Chimichagua generalmente inicia con el coro y luego se le van agregando los versos, por ejemplo [él empieza a cantar] fue en un baile de mi pueblo [coro] ella me decía que no, [verso] donde yo la enamoraba [coro] ella me decía que no. Esto es un ejemplo de una tambora que se adapta a paseo vallenato y se le llama tamborera [...] El berroche de aquí uno lo puede convertir en paseo rápido también, varios grupos han grabado mis canciones con ese cambio $[\ldots]$ y la particularidad es que ya los versos se van alargando. ${ }^{85}$

Al escuchar a los cultores de la tambora chimichagüera se evidencia cómo esta manifestación todavía goza de vigencia entre las comunidades musicales imaginadas de los bailes cantaos. De este modo, han configurado socialmente su conocimiento

82. Lo extra-musical entendido como lo precisa el Diccionario de la lengua española, extra "Del lat. extra", en conjunto significa "fuera de" lo musical. Real Academia Española, Diccionario de la lengua española (España: Espasa Calpe, 1992) 663.

83. Ciro A. Quiroz, Vallenato, hombre y canto (Bogotá:Asociación de Escritores del Caribe, 2004) 11.

84. Entrevista de Bernardo A. Ciro Gómez a Diógenes A. Pino, Tamalameque, Cesar, 2 de diciembre de 2017.

85. Entrevista de Bernardo A. Ciro Gómez a Luis Cadena, Chimichagua, Cesar, 28 de noviembre de 2017. Esta es una lectura con carácter demostrativo. La mencionada reapropiación musical será objeto de un análisis musicológico para un posterior texto. Por lo pronto, en los siguientes se puede escuchar y comparar "La perra" en paseo y cantada por Alejo Durán en Colección Beto Mireles, "La perra-Alejo Duran (con letra) Ay hombe!!!”, YouTube video 2:49, 9 de febrero de 2018. www.youtube.com/watch?v=6O-7PSywYgI, con "La perra" en tambora chimichagüera cantada por Héctor "Chichi" Rapalino en Bernardo A. Ciro Gómez, "'La Perra' tambora de Heriberto Pretel. Chimichagua Cesar. Grabación: Bernardo A. Ciro Gómez”, YouTube video 1:44, 6 de septiembre de 2018. www.youtube.com/ watch? $v=j 8 x y R p G j H C U \& t=28$ s. 
de la música "fuera de" o en la periferia de los proyectos nacionales de cultura. Estas comunidades musicales imaginadas se extienden por todo el sur de la Depresión Momposina con mucha fuerza, a pesar de la indiferencia de la industria musical y de estar aparentemente a espaldas de la historia oficial de la música colombiana.

\section{Fuentes}

\section{Manuscritas}

Biblioteca Carlos Gaviria Díaz, Universidad de Antioquia, Medellín (BCGD) Fondo Archivos Personales

Archivo Parroquia de la Inmaculada Concepción de Chimichagua, Chimichagua (APICC)

\section{Internet}

cesar.gov.co/d/index.php/es/ (2018)

http://www.discogs.com (2017)

http://www.eluniversal.com.co (2014)

http://www.idep.edu.co (2016)

www.noticiasrcn.com (2018)

www.youtube.com $(2015,2018)$

\section{Bibliografía}

Anderson, Benedict. Comunidades imaginadas. Reflexiones sobre el origen y la difusión del nacionalismo. México: Fondo de Cultura Económica, 2013.

Barriga, Martha. "El afro-colombiano en la educación musical desde la Colonia hasta principios del siglo XX”. El Artista 9 (2012): 244-353.

Bermúdez, Egberto. "Jacques Gilard y la música popular colombiana”. Caravell 93 (2009): 19-40.

. ¿Qué es el vallenato? Una aproximación musicológica”. Ensayos. Historia y Teoría del Arte 9.9 (2004): 9-62

Biblioteca Aldeana de Colombia. Cancionero escolar. Bogotá: Biblioteca Aldeana de Colombia, 2012.

Blanco, Darío. "La música de la Costa Atlántica colombiana. Transculturalidad e identidades en México y Latinoamérica”. Revista Colombiana de Antropología 41 (2005): 171-203

Ciro Gómez, Bernardo A. y Jhon Eduard Ciro Gómez. "Etnografía musical en el río Magdalena. El son de Berroche de la subregión de Loba". Periferia 20.2 (2015): 125-160. 
Gilard, Jacques. "Vallenato. ¿Cuál narrativa?”. Huellas. Revista de la Universidad del Norte 19 (1987): 59-67.

Gobernación del Cesar."Plan de Desarrollo. Departamento del Cesar 2016-2019. El camino del desarrollo y la paz". Documento oficial, Gobernación del Cesar, 2016.

"Plan estratégico regional de ciencia, tecnología e innovación del departamento del Cesar 2007-2011”. Documento oficial, Gobernación del Cesar / Universidad Nacional de Colombia, 2007.

González, Adolfo. "La música costeña en la tercera década del siglo XIX”. Boletín Cultural y Bibliográfico 26.19 (1989): 4-21.

Gutiérrez, Tomás D. Cultura vallenata. Origen, teoría y pruebas. Bogotá: Panamericana, 2014.

Instituto Caro y Cuervo. Atlas lingüístico etnográfico de Colombia. Ganadería, animales domésticos y animales silvestres. Tomo 2. Bogotá: Instituto Caro y Cuervo, 1982.

Keil, Charles. "Las discrepancias participatorias y el poder de la música”. Las culturas musicales, lecturas de etnomusicología. Eds. Francisco Cruces y otros. Madrid: Editorial Trotta, 2008.

Medina, Ismael. Chimichagua en la memoria de los abuelos. Cali: Arte Libro Impresores, 2005.

. Mi Chimichagua de ayer. Cali: Arte Libro Impresores, 1990.

Mignolo, Walter. Habitar la frontera, sentir y pensar la descolonialidad. Barcelona: CIDOB / Universidad Autónoma de Ciudad Juárez,2015.

Ministerio de Instrucción Pública. Memoria del ministro de Instrucción Pública al Congreso Tomo I. Bogotá: Casa Editorial de la Cruzada, 1923.

Perdomo, José Ignacio. Historia de la música en Colombia. Bogotá: Plaza \& Janes Editores, 1980.

Quiroz Otero, Ciro. Vallenato, hombre y canto. Bogotá:Asociación de Escritores del Caribe, 2004.

Real Academia Española. Diccionario de la lengua española. Madrid: Espasa Calpe, 1992.

Rendón Marín, Héctor. De liras a cuerdas. Una historia social de la música a través de las estudiantinas. Medellín 1940-1980. Tesis de Maestría en Historia, Universidad Nacional de Colombia, sede Medellín, 2009.

Rojas, Cristina. Civilización y violencia. La búsqueda de la identidad en la Colombia del siglo XIX. Bogotá: Pontificia Universidad Javeriana, 2001.

Runge,Andrés y Diego Muñoz. “Actividad vs. agitación en el pensamiento de Luis López de Mesa: relaciones entre pedagogía y eugenesia en la Colombia de principios del siglo XX". Revista Colombiana de Educación 1.61 (2011): 21-51.

Sagredo, Humberto. "El ritmo en la música venezolana”. Revista Musical de Venezuela 25 (1988): 47-107.

Santana, Sergio. Lucho Bermúdez. Cumbias, porros y viajes. Medellín: Ediciones Santo 
Bassilón, 2012.

Silva, Renán. "Encuesta Folclórica Nacional, 1942 (Instrucciones para el posible lector)". Historia y Espacio 18 (2002): 7-43. . "Encuesta Folclórica Nacional, 1942. Presentación de la Encuesta y esbozos de un primer resultado". Anuario de Investigaciones de la Universidad del Valle (2001): 375-391.

. "Libros y lecturas durante la república liberal: Colombia, 19301946”. Revista Sociedad y Economía 3 (2002): 141-169.

Talero, María Elvira. Coord. "Gloria Triana”. Cinemateca. Cuadernos de Cine Colombiano 24 (1987).

Tirado Mejía, Álvaro. "Colombia. Siglo y medio de bipartidismo”. Colombia Hoy, coord. Jorge Orlando Melo. Bogotá:Tercer Mundo Editores, 1995.

Wade, Peter. Música, raza y nación. Música tropical en Colombia. Bogotá:Vicepresidencia de la República, 2002. 